\title{
Organ Utilization From Deceased (Non-Herat-Beating) Donors
}

\author{
Ihsan Yıldız \\ Department of General Surgery, Suleyman Demirel University, Çünür, Isparta, Turkey
}

Corresponding author: Ihsan Y,ldiz, MD

Suleyman Demirel University Çünür 32260 Isparta, Turkey

E-mail: drihsanyildiz@gmail.com
Dear Editor,

We read with great interest the article entitled "Two and a Half Hours of Cardiopulmonary Resuscitation in a Deceased Brain Dead Donor before Liver Transplantation - A Good Idea to Accept?" by Dieter P. Hoyer et al. (1) published in Chirurgia. Undoubtedly, the labor and methods given to overcome the limitations of the demand of organs are always appreciated (1). We would be pleased if they may clarify some unclear issues about your study. Did they use the kidneys of the donor for one or two recipients? If not, why?

In a similar study, for overcoming similar difficulties we used Maastricht classification for evaluating non-heart-beating donors. All of our cases belonged to the controlled condition of Maastricht Category 4 (developing arrest while awaiting). The average donor risk index (KDRI) and (KDPI) of the cases were $0.9452(0.854-1.161) 45 \%(35-65 \%)$ respectively(2). We used the organs within acceptable limits in terms of imaging and labarotory parameters.

However, in 4 patients who developed cardiac arrest, after i.v. heparin infusion (5000-10000U) and cardiac resuscitation, the organs were harvested after emergency laparotomy was performed and the abdomen was cooled with cold saline and the organs were removed in a cold environment and perfused on the back-table. Nevertheless, in these cases vascular and parenchymal damage has occurred due to rush during operation and technical difficulties. Warm ischemia time of the 4 cases was also longer than other cases. The warm ischemia time was averagely 11 minutes (interquartile range; 6 -15) for 9 cases and 20 minutes (interquartile range, 15-25) for 4 NHBDs (3). 
Additionally in the study of Dieter P. Hoyer et al, the mean warm ischemia time was longer than our cases. May they explain the reason for this result?

As a result, although non-heart-beating donors have not established a criterion in terms of time for organ harvesting, we think that cases with normal organ function should be solid organ donors.

\section{References}

1. Hoyer DP, Kaiser GM, Paul A, Machairas N, Molmenti EP, Sotiropoulos GC. Two and a Half Hours of Cardiopulmonary Resuscitation in a Deceased Brain Dead Donor before Liver Transplantation - A Good Idea to Accept? Chirurgia (Bucur). 2017;112(1):46-49. doi: 10.21614/chirurgia.112.1.46.

2. Martin-Villen L, Revuelto-Rey J, Aldabo-Pallas T, Correa-Chamorro E, Gallego-Corpa A, Ruiz Del Portal-Ruiz Granados P, et al. NonHeart-Beating Donor Program: Results After 3 Years of Experience. Transplant Proc. 2015;47(9):2567-9. doi: 10.1016/j.transproceed. 2015.09.050.

3. Yıldız I, Koca YS, Sabuncuoglu MZ. Organ Retrieval from NonHeart-Beating Donor with Declared Brain Death: Harvest at Arrest. Chirurgia (Bucur). 2017;112(2):130-35. http://dx.doi.org/10. 21614/chirurgia.112.2.130 